\title{
O OLHAR PÓS-MODERNO: UMA LEITURA DE PALOMAR
}

\author{
Risolete Maria Hellmann \\ Doutoranda em Literatura - UFSC
}

\section{RESUMO}

Este estudo empreende uma leitura, ou um olhar, possível sobre a obra Palomar, de Ítalo Calvino, situada no cenário pós-moderno. A narrativa valoriza o sentido da visão na criação literária, transformando-a em ficção crítica, na medida em que aponta para categorias de análise valorizadas na pós-modernidade: fragmentação, narração, leitura, autoria, identidade, realidade virtual, entre outras.

\section{PALAVRAS-CHAVE}

Leitura; Olhar; Ficção crítica.

\section{THE LOOK POSTMODERN: A READING OF PALOMAR}

\section{ABSTRAC}

This study undertakes a possible reading, or looking, of the work Palomar, written by Ítalo Calvino, located in the post-modern. The narrative emphasizes the sense of sight in literary creation, transforming it into fiction criticism, as it points to categories of analysis valued in post modernity: fragmentation, storytelling, reading, authorship, identity, virtual reality, between.

\section{KEYWORDS}

Reading; Look; Criticism fiction. 
Contemporaneamente somos lançados em narrativas onde o tempo é fragmentado, deslocado, repetitivo e, muitas vezes, míope. Palomar, de Ítalo Calvino, é uma montagem (como uma montagem cinematográfica) de pequenas narrativas, que se constroem a partir de percepções breves. A obra é constituída de fragmentos, de cacos recuperados pelo olhar da personagem. Esta percorre e amarra todos esses cacos em uma narrativa crítico-ficcional mais ampla. O olhar é o fio condutor que interliga essas pequenas narrativas. Na obra em estudo, a linguagem metafórica e metonímica reflete e/ou refrata o pensamento da crítica pós-moderna e o autor trabalha categorias como: fragmentação, narração, leitura, autoria, construção textual, trabalho da citação, identidade, alteridade, realidade virtual e vivências maquínecas. Isso nos permite pensá-la como obra representativa do pós-modernismo que sustenta uma ruptura radical, um corte em relação ao modernismo, pois como define Huyssen (1992, p.22):

Em quase todo o debate sobre o pós-modernismo, um modo de pensar
muito convencional tem se firmado. Ou se diz que o pós-modernismo
está em continuidade com o modernismo, caso em que todo debate
que oponha os dois fenômenos passa a ser ilusório, ou se sustenta que
há uma ruptura radical, um corte em relação ao modernismo, que é
então avaliado em termos positivos ou negativos.

Nos vários debates acerca da modernidade e pós-modernidade, despontaram alguns posicionamentos como: a apologia à chegada dos tempos pós-modernos e a consequente revolução no pensamento; a crítica à farsa pós-moderna que obscurece a nossa visão e vê este momento como um resgate do caráter crítico do modernismo; e os que não se preocupam em nomear ou classificar esse momento em que se pensa as transformações ocorridas no mundo e os desafios que se colocam a cada dia, como a emergência das novas identidades coletivas. Na prática, pode-se pensar em duas formas de pós-modernismo: um pós-modernismo de reação que, articulado com um neoconservadorismo, critica e repudia o modernismo, culpando suas práticas sociais como os males sociais (modernização), ao mesmo tempo que defende a manutenção do status quo econômico e político; o pós-modernismo de resistência, o qual toma a crítica da modernidade como forma de opor-se à manutenção do status quo e surge como uma contra-prática da cultura oficial do modernismo, mas também de uma falsa normatividade do pós-modernismo reacionário.

O que, de fato, ainda é válido é a investigação a fundo do projeto moderno, tanto em seus aspectos epistemológicos quanto em seus aspectos políticos, assim como 
a investigação aprofundada dos aspectos epistemológicos e políticos de propostas contemporâneas do pós-modernismo precisam ser estudadas. Pois, como afirma Huyssen (1992, p.22):

[...] uma vez irreversível a sumária lógica da expansão do pósmodernismo, o labirinto do pós-moderno tornou-se ainda mais impenetrável. No início dos anos 80 , a constelação modernismo/pósmodernismo nas artes e a constelação modernidade/pós-modernidade na teoria social tinham já se transformado em um dos mais disputados campos da vida intelectual das sociedades ocidentais. E o campo é disputado precisamente porque há muito mais em questão do que a existência ou não de um novo estilo artístico, e bem mais do que simplesmente a 'correta' linha teórica.

Assim, ao pensar na obra de Calvino, sem a pretensão de classificar um novo estilo artístico, arriscamo-nos numa incursão, talvez perigosa, pois não há, a princípio, uma relação direta entre a teoria pós-moderna e a interpretação do fenômeno literário. No entanto, a leitura de Palomar de Ítalo Calvino nos remete a fragmentos de um olhar pós-moderno. Nela, percebemos a importância do olhar que informa, funciona como instrumento útil e prazeroso. É uma espécie de câmera que viaja pelo cotidiano da personagem e dela repassa imagens ao leitor através da palavra/linguagem. Esse olhar capta não só a aparência das coisas, mas também os sentidos que nos relacionam a essa aparência. O leitor/olhador (neologismo nosso) de mundo se inscreve nessa leitura, pois, como diz Barthes (1988, p.44), “[...] o leitor não se oculta no texto, só não pode ser localizado". Em outras palavras, o sujeito da leitura/escritura está crivado no texto, o que permite o encontro de múltiplas vozes: do autor, do narrador, da personagem, do leitor, da crítica, entre outras.

\section{AUTOR, NARRADOR, PERSONAGEM: OS OLHOS QUE OLHAM}

Calvino (1994, p.102) indaga: "de quem são os olhos que olham?" E nós completamos: de quem é a voz que fala na obra? Na obra Palomar, o autor se investe do narrador e este da personagem. Suas vozes estão hibridizadas e perpassadas pela leitura de outros textos.

O sujeito autor, nessa obra, é fragmentado e coloca-se sem "genialidade", uma vez que a concepção simbólica do autor como pai textual já teve morte decretada (BARTHES, 1984, p.49-53). Não há mais autor indivíduo, há um sujeito esfacelado, há 
vestígios dele no texto como marca autobiográfica que o personaliza. O autor, Ítalo Calvino, fica no objeto, obra, como uma assinatura.

O narrador, por sua vez, é uma voz onisciente por trás de Palomar (personagem), que informa a partir da observação, da contemplação. Deixa-se invadir pelo olhar da personagem, ao mesmo tempo em que imprime seu próprio olhar sobre o observado.

Como coloca Santiago (1989), o narrador pós-moderno é o que transmite uma sabedoria que é decorrência da observação de uma vivência alheia a ele, visto que a ação que narra não foi tecida na substância viva da sua existência. Nesse sentido, ele é o puro ficcionista, pois tem de dar autenticidade a uma ação que, por não ter o respaldo da vivência, estaria desprovida de autenticidade. Esta advém da verossimilhança que é produto da lógica interna do relato. O narrador pós-moderno sabe que o real e o autêntico são construções de linguagem. "A coisa narrada é mergulhada na vida do narrador e dali retirada; [...] é vista com objetividade pelo narrador, embora este confesse tê-la extraído da sua vivência; [...] existe como puro em si, ela é informação, exterior à vida do narrador." (SANTIAGO, 1989, p.40)

O narrador pós-moderno de Palomar não traz mais o fantasma da visão onisciente, o olho de Deus, do Sol, do Pai. Não tem a ambição de desafiar o Pai, daí frequentemente questionar: "[...] será o gramado aquilo que vemos ou vemos antes uma erva e mais outra e mais outra...?" (CALVINO, 1994, p.32). E se investe do olhar de Palomar à procura de explicações:

O senhor Palomar está arrancando as ervas, de cócoras no gramado. [...] Quando se começa por erradicar uma gramínea, logo se vê apontar outra, e mais outra, e outra mais. Em suma, aquela fímbria de tapete herboso que só parecia requerer uns poucos retoques revela-se uma selva incontrolável. [...] 'certamente, arrancar uma erva daninha aqui e outra ali não resolve nada. Seria necessário proceder da seguinte forma', pensa ele, 'tomar um quadrado do gramado [...] e extirpá-lo até da mais ínfima presença que não seja grama, joio ou trevo [...] Contar quantos fios de erva existem, verificar de que espécie são, qual sua densidade e como se distribuem. Com base nesse cálculo se chegará a um conhecimento estatístico do gramado, estabilidade que [...]' Mas contar os fios de erva é inútil, jamais se chegará a saber quantos são. Um gramado não possui limites [...] (CALVINO, 1994, p.30)

O narrador de Calvino é antes de tudo um leitor que "[...] conta ou reconta, mas sobretudo decifra e comenta"(ARRIGUCCI,1987, p.231), por meio de metáforas e metonímias, os fantasmas da crítica contemporânea, como, por exemplo, a presença de 
outras vozes no texto/gramado, através das citações. O desejo de limpar o texto, estabelecer procedimentos científicos para tal, é ilusório e, acima de tudo, inútil uma vez que um texto não possui limites. Essa sua reflexão o conduziu à definição do gramado/texto:

O gramado é um conjunto de ervas [...] que inclui um subconjunto de ervas cultivadas e um subconjunto de ervas espontâneas ditas daninhas, uma interseção dos dois subconjuntos é constituída pelas ervas nascidas espontaneamente mas que pertencem a espécie cultivadas e portanto indistinguíveis dessas [...] (CALVINO, 1994, p.31)

O texto é constituído de citações daninhas - aquelas que se inscrevem até contra nossa vontade, citações cultivadas por meio de nossas leituras e aquelas citações que se misturam ao nosso discurso, que ficam nas entrelinhas e são, portanto, indistinguíveis. No entanto, é preciso pensá-las: “[...] o que importa é fixar com um único golpe de vista as plantinhas individuais uma por uma, em suas particularidades e diferenças, e não apenas vê-las: pensá-las”. (CALVINO, 1994, p.32)

A citação é uma erva daninha no texto, mesmo que se arranque o superficial, as raízes ficam, se alastram e brotam nas entrelinhas. Daí um gramado/texto não ter limites. A continuidade de um texto plural depende do tipo de leitor que o olha/lê.

Tanto o narrador, quanto a personagem estão conscientes dos fantasmas que os cercam e se fazem leitores das citações encontradas. As citações aparecem como técnicas de reprodução de condições do passado que se presentificam. Elas são eventos passados artificiais que invadem o seu presente, o cenário contemporâneo, como podemos ver em: "[...]já durante milhões de séculos os raios de sol pousaram sobre a água antes que existissem olhos capazes de recolhê-los." (CALVINO, 1994, p.18)

Textos de todos os tempos traziam citações de autores anteriores, mas somente no século $\mathrm{XX}$ as preocupações acerca da paternidade textual vieram à tona:

Um dia um olho saiu do mar, e a espada, que já estava ali à sua espera, pôde finalmente ostentar toda a esbelteza de sua ponta aguda e seu fulgor cintilante. Tinham sido feitos uma para o outro, a espada e o olho: e talvez não tenha sido o nascimento do olho que tenha feito nascer a espada, mas vice-versa, porque a espada não podia recusar um olho que a observasse de seu vértice. (CALVINO, 1994, p.19)

Em nenhuma outra época o escritor se deu conta de que a linguagem é multifária e perdeu toda a rígida conotação semântica. 
O autor/leitor ao se defrontar com as vozes de outros autores não pode recusálas, é como se tivessem "[...] sido feitos um para o outro". A citação/espada que o olhar encontra, "à sua espera", colabora na morte do pai textual:

Se vejo e penso e nado no reflexo, é porque no outro extremo está o sol lançando seus raios. Só conta a origem do que é: algo que meu olhar não pode suster senão de forma atenuada como neste entardecer. Todo o resto é reflexo entre reflexos, inclusive eu. (CALVINO, 1994, p.17)

Arrigucci (1987, p.228) afirma que "[...] o leitor identificado com a sua imagem refletida, passa de indagador a indagado e [...] deve decifrar o enigma da origem da literatura, onde ficou perdida sua face." Ítalo Calvino admite um "sol lançando seus raios", mas considera a busca de fontes e origens vã, uma vez que o resto são citações entre citações que seu "olhar não pode suster senão de forma atenuada":

$\mathrm{O}$ eu flutuante do senhor Palomar está imerso num mundo desincorporado, interseções de campos de forças, diagramas vetoriais, feixes de retas que convergem, divergem, se refrangem. Mas dentro dele permanece um ponto onde tudo existe de outro modo, como um nó, um coágulo, um obstáculo: a sensação de que está aqui mas poderia não estar, num mundo que poderia ser mas não é. (CALVINO, 1994, p.18)

Por um lado, Palomar é um leitor crítico que se questiona e tem consciência da realidade fragmentada e caótica que o cerca, no entanto em seu universo interior sempre permanecem pontos obscuros, ofuscados e uma sensação de incompletude. Por outro lado, Palomar é um sujeito humilde da leitura/escritura, que ensaia várias formas/modos de olhar/ler, experimenta vários ângulos, mas esse olhar não é um reflexo do universo, pois a visão é refratada, o mundo é um simulacro nessa atividade crítica-reflexiva.

Nas palavras de Santiago, 1989,p.48):

O olhar humano pós-moderno é desejo e palavra que caminham pela imobilidade, vontade que admira e se retrai inútil, atração por um corpo que, no entanto, se sente alheio à atração, energia própria que se alimenta vicariamente de fonte alheia. Ele é o resultado crítico da maioria das nossas horas de vida cotidiana.

Nessa montagem ambivalente de olhares constitui-se a alteridade na medida em que um eu se desdobra em outro. Como Barthes (1984, p.49) questiona na sua leitura da novela de Balzac, também podemos perguntar: de quem é a voz que fala numa obra? do herói personagem? do indivíduo autor? da Sabedoria Universal? E concluímos 
como ele que é impossível sabê-lo, pois são múltiplas as vozes que se cruzam na obra. Por isso, se faz necessário um leitor capaz de interpretar essas múltiplas vozes.

\section{A EMERGÊNCIA DE UM LEITOR DE ONDAS/LEXIAS}

Considerando a importância dos leitores nos textos contemporâneos, apontada pela crítica literária a partir da estética da recepção, Ítalo Calvino apresenta características desses que enveredam pelos gramados repletos de ervas e consequentemente acabam escrevendo sua leitura. Ele apresenta, ao longo da narrativa, diversas faces de leitores, descritos a seguir.

Inicialmente apresenta um leitor que é lua ao entardecer, como se observa em "Ninguém observa a lua do entardecer, e no entanto é nesse momento que o nosso interesse por ela seria mais necessário, já que sua existência encontra-se ainda em estado de expectativa." (CALVINO, 1994, p.33). Sua existência ainda é precária e ele ainda se alimenta da luz do outro, o sol, mas está em 'estado de expectativa', isto é, vai brilhar por toda a noite.

Um segundo leitor reconhece suas deficiências visuais e, por isso, aumenta seu grau de interesse, como coloca Calvino (1994, p.36): “O senhor Palomar, tendo sabido que este ano durante todo o mês de abril os três planetas 'externos' visíveis a olho nu (mesmo por ele que é míope e astigmático) estarão 'em oposição', portanto visíveis por toda a noite, apressa-se em subir ao terraço." Esse leitor, além disso, preocupa-se em munir-se de máquinas que ampliem sua visão: “[...] é indispensável munir-se de um telescópio." (CALVINO, 1994, p.36).

Em outro momento, aparece um leitor que interrompe a leitura por afluxo de idéias, de excitações, de associações, que sente necessidade de interrogar a própria leitura, de captar a forma de todas as leituras e acabe escrevendo textos (na sua mente) durante as interrupções:

[...] não consegue manter a imagem nítida: necessita fechar por um momento as pálpebras, deixar que a pupila ofuscada reencontre a percepção precisa dos contornos, das cores, das sombras, mas também deixar que a imaginação se livre dos embaciamentos que não lhe pertencem, renuncie a ostentar uma sabedoria livresca. (CALVINO, 1994, p.39)

Um quarto tipo de leitor, apresentado por Calvino (1994, p.40), se apropria do que vê/lê: "Assim espera haver se apropriado de fato do planeta, ou pelo menos do 
quanto de um planeta pode entrar em um olho". É uma apropriação não plena, mas somente daquilo que o sujeito é capaz de absorver a partir de sua perspectiva.

Um quinto leitor se aproxima de Palomar, pois é "todo olhos", é telescópio ao contrário, pois amplia as coisas próximas do cotidiano:

[...] a escolha entre a televisão e o réptil não ocorre sem incertezas; os dois espetáculos têm cada um deles informações para dar que o outro não transmite: a televisão se move pelos continentes recolhendo impulsos luminosos que descrevem a face visível das coisas; o camaleão ao contrário representa a concentração imóvel e o aspecto oculto, o contrário daquilo que se mostra à vista. (CALVINO, 1994, p.53)

E opta por desvendar o lado oculto, o contrário do que se mostra à vista.

Por fim, aparece um leitor antropofágico (no sentido oswaldiano) que devora suas presas para alimentar-se até que ele mesmo seja devorado por outro ventre:

Talvez nesse exato momento um deus dos infernos situados no centro da terra, com seu olhar que atravessa o granito, esteja nos olhando lá de baixo, seguindo o ciclo da vida e da morte, as vítimas dilaceradas que se desfazem nos ventres dos devoradores, até que por sua vez um outro ventre também o engula. (CALVINO, 1994, p. 55)

O próprio Ítalo Calvino reconhece o olhar como leitura ao abrir a narrativa com o subtítulo: "Leitura de uma onda" (CALVINO, 1994, p.7). Além disso, seu narrador tem sempre a preocupação em definir suas metáforas: "ondas [...] são formas e sequências que se repetem ainda que distribuídas de modo irregular no espaço e no tempo". (CALVINO, 1994, p.8) São as lexias que se repetem nos textos de tempos e espaços diversos. Essa distribuição irregular está relacionada ao modo de ver/ler que muda conforme os contextos de tempo e espaço sócio-histórico-culturais. Como diz o próprio narrador de Palomar: "[...] não se pode observar uma onda sem levar em conta os aspectos complexos que concorrem para formá-la e aqueles também complexos a que essa dá ensejo.” (CALVINO, 1994, p.8)

O olho que informa (in)diretamente, mesmo que em fragmentos, caminha no movimento das ondas: "O senhor Palomar vê uma onda apontar na distância, crescer, aproximar-se, mudar de forma e de cor, revolver-se sobre si mesma, quebrar-se, desfazer-se." (CALVINO, 1994, p.7). Esse movimento envolve o leitor antropofágico, indivíduo em busca de sua identidade, de seu lugar no Universo, que quer sempre delimitar, enquadrar tudo pelo ângulo da visão, em campos experimentais: 
Ele procura [...] limitar seu campo de observação; se tem presente um quadrado [...] pode levantar um inventário de todos os movimentos de ondas que ali se repetem com freqüência variada dentro de um dado intervalo de tempo. A dificuldade está em fixar os limites desse quadrado, porque [...] se ele considera como o lado mais distante de si a linha em relevo de uma onda que avança, essa linha ao aproximar-se dele irá, erguendo-se, ocultar de sua vista tudo o que está atrás; e eis que o espaço tomado para exame se destaca e ao mesmo tempo se comprime. (CALVINO, 1994, p.7)

No entanto, frequentemente, defronta-se com dificuldades, uma vez que toda visão parcial é relativa. E evidencia a impossibilidade de alcançar a totalidade: "[...] a cada momento acredita haver conseguido observar tudo o que poderia ver de seu ponto de observação, mas sempre ocorre alguma coisa que não tinha levado em conta". (CALVINO, 1994, p.9). O que se apresenta como outro fantasma para o leitor/autor, impedindo que ele conclua sua análise, uma vez que a imagem, formada a partir de um cenário em movimento constante, "se desfigure, se fragmente e se perca" constantemente.

É pena que a imagem que o senhor Palomar havia conseguido organizar com tanta minúcia agora se desfigure, se fragmente e se perca. Só conseguindo manter presentes todos os aspectos juntos, ele poderia iniciar a segunda fase da operação: estender esse conhecimento a todo o universo. (CALVINO, 1994, p.11)

\section{EM BUSCA DA IDENTIDADE}

O olhar de Palomar parte do universo exterior (físico) - enquanto espaço mais aberto- para chegar ao seu próprio interior - como espaço fechado - em busca da sua identidade. A partir dos lugares dos quais ele pensa, reflete, busca explicações para a existência, para seu lugar no universo, cria-se um processo de identificação e desidentificação. Ele se apresenta na ótica do sujeito que vê a significação do mundo.

[...] contemplar as coisas pelo seu exterior. Um tanto míope, alheado, introvertido, ele não parece ajustar-se por temperamento ao tipo humano que é geralmente definido como observador. Contudo [...] determinadas coisas [...] se apresentam a ele como se lhe solicitassem uma atenção minuciosa e prolongada: ele se põe a observá-las quase sem dar conta disso e seu olhar começa a percorrer todos os detalhes, e não consegue mais parar.[...] se esquivar a esses reclamos que lhe vêm das coisas [...] atribuir à operação de observar a importância que ela merece. (CALVINO, 1994, p.101) 
A paixão pela busca da identidade é, segundo Sucre (1979, p.226), "[...] o reino da lucidez e da imaginação, a aliança entre a reflexão crítica e o impulso criador". Palomar se apropria do mundo pelo olhar, um espaço pleno de representação onde ele se inscreve enquanto olha.

\begin{abstract}
Mas como é possível observar alguma coisa deixando à parte o eu? [...] Em geral se pensa que o eu é algo que nos está saliente dos olhos como o balcão de uma janela e contempla o mundo que se estende em toda a sua vastidão diante dele. [...] mundo que observa e mundo que é observado [...] E o senhor Palomar? Não será também ele uma parte do mundo que está olhando a outra parte do mundo? [...] Para contemplar-se a si mesmo o mundo tem necessidade de olhos (e de óculos) do senhor Palomar. (CALVINO, 1994, p.102)
\end{abstract}

A busca do eu é feita a partir da correspondência no ato de olhar/ler. A leitura participa da própria criação, já que é um diálogo com o texto. Para Barthes (1988, p.45), "[...] ler é um trabalho de linguagem [...] é encontrar sentidos e encontrar sentidos é nomeá-los [...] é uma nomeação em devenir, uma aproximação incansável, um trabalho metonímico." Nem Palomar, nem o narrador almejam a totalidade dessa identidade. Eles se sabem incompletos, fragmentados e flutuantes.

Ítalo Calvino é um autor/leitor que também tenta decifrar, através do narrador e de Palomar, sua face perdida em meio às imagens refratadas, fragmentadas, por eles criadas: “'Não podemos conhecer nada exterior a nós se sairmos de nós mesmos”, e acrescenta, "o universo é o espelho em que podemos contemplar só o que tivermos aprendido a conhecer em nós". (CALVINO, 1994, p.107)

Assim como a imagem repetida nos textos borgeanos, surge na obra a imagem de um leitor de si mesmo, um decifrador movido "[...] por uma inabalável curiosidade intelectual, pressupondo uma idêntica atitude inquisitiva diante dos livros e do Universo". (ARRIGUCCI, 1987, p.229)

\title{
NA ERA DA ROBOTIZAÇÃO
}

Para Lyotard (1986, p.3-4), “[...] o saber muda de estatuto ao mesmo tempo que as sociedades entram na idade dita pós-industrial e as culturas na idade dita pósmoderna[...]" e considera que a pesquisa e a transmissão dos conhecimentos será afetado pela incidência das informações tecnológicas sobre o saber. Nesta era tecnológica, a natureza do saber também mudará, pois tanto os produtores, quanto os 
utilizadores devem e deverão ter os meios de traduzir em linguagens quantificadas o que alguns buscam inventar e outros aprender. Neste sentido, "o antigo princípio segundo o qual a aquisição do saber é indissociável da formação (Bildung) do espírito, e mesmo da pessoa, cai e cairá cada vez mais em desuso". Calvino (1994, p.87) descreve a era da robotização com olhos para a vida:

Que vê? Vê a espécie humana na era dos grandes números estendendo-se numa multidão nivelada mas feita de individualidades distintas como esse mar de grãozinhos de areia que submerge a superfície do mundo [...]Vê o mundo nada obstante continuar a mostrar os dorsos de granito de sua natureza indiferente ao destino da humanidade, sua dura substância irredutível à assimilação humana [...] Vê as formas em que a areia humana se agrega tenderem a dispor-se segundo linhas de movimento, desenhos que combinam regularidade e fluidez como os traços retilíneos de um ancinho [...] E entre humanidade-areia e mundo-escolho intui-se uma harmonia possível como entre duas harmonias não homogêneas: a do não-humano num equilíbrio de forças que parece não corresponder a nenhum desenho; a das estruturas humanas que aspira a uma racionalidade de composição geométrica ou musical, jamais definitiva $[\ldots]$

O olhar encontra um cenário contemporâneo fragmentado, caótico, contraditório, mas que deseja alcançar a harmonia, mesmo sabendo-se não-definitiva, porque vivemos num mundo em movimento. Bauman (1999, p.67), comentando a "nova desordem mundial", diz que "o significado mais profundo transmitido pela idéia da globalização é o de caráter indeterminado, indisciplinado e de autopropulsão dos assuntos mundiais; a ausência de um centro, de um painel de controle, de uma comissão diretora [...]" que restabeleça a ordem entre Nação-Estado e a política social e econômica. Dessa forma, o mundo globalizado social e economicamente está cada vez mais fragmentado, como o mar de grãozinhos de areia descritos por Palomar.

Ainda para Bauman (1999, p.63), a velocidade em que o mundo se movimenta (aproximada a do sinal eletrônico) aniquila as restrições espaciais de onde algo partiu e ao qual se dirige, assim como se tem a superação da gravidade. Daí a multidão nivelada que se dispõem segundo linhas de movimento e combinam regularidades e fluidez.

O cenário contemporâneo, por não estar pronto e acabado, apresenta rupturas e fendas. E, num processo de desnaturalização, como coloca Gumbrecht (1998), na era do computador temos "um Eros eletrônico", para usar as palavras de Calvino (1994). Ainda segundo Gumbrecht (1998, p.138): “Em nossa práxis cotidiana perdemos progressivamente um contato direto, a fricção do corpo com a matéria [...] Esta perda traz consigo a sensação de enfraquecimento do nosso contato com o mundo externo". E, 
por meio da realidade virtual, vivenciamos nossas emoções com o outro maquinalmente, como no fragmento a seguir:

Ele as observa com fria atenção, como se se tratasse de duas máquinas: duas tartarugas eletrônicas programadas para se acasalarem [...] de nossos receptores partem milhares de fios, ligados ao computador dos sentimentos, dos condicionamentos, dos vínculos entre as pessoas [...] O Eros é um programa que se desenvolve nos emaranhados eletrônicos da mente, mas a mente também é pele: pele tocada, vista, recortada. [...] A penúria de estímulos sensoriais as obriga a uma vida mental concentrada, intensa, leva-as a um conhecimento interior cristalino [...] (CALVINO, 1994, p.22)

O autor contemporâneo usa a imagem obtida a partir da observação, da contemplação na construção da sua narrativa. Ele tem consciência da importância do olhar enquanto instrumento narrativo. Palomar, ao utilizar os óculos e os binóculos (às vezes pelo avesso) e demonstrando sua preocupação em ampliar o cotidiano, em fazer os recortes adequados, em escolher os espaços mais ilustrativos para olhar/ler, funciona como uma câmera nas mãos do narrador. O personagem é máquina usando instrumentos maquínicos.

No entanto, segundo Blanchot (1987, p.176) o "[...] olhar é o movimento do desejo que quebra o destino". É o que vamos ver a seguir.

\section{UM OLHAR NO TEMPO: SUCESSÃO E MUDANÇA}

O olhar de Ítalo Calvino apresenta os preconceitos retrógrados quando Palomar esbarra com a nudez de um seio feminino na praia:

Ao ver o seio nu de uma jovem estendida na areia [...] volve o olhar para o horizonte marinho [...] o tabu da nudez fica implicitamente confirmado [...] E ele pensa; [...] o meu não-olhar pressupõe que eu esteja pensando naquela nudez, que me preocupe com ela, e isto é, no fundo, ainda uma atitude indiscreta e retrógrada. (CALVINO, 1994, p.12)

E questiona o leitor por meio do narrador: “Mas esse sobrevôo de olhar não poderia afinal de contas ser compreendido como uma atitude de superioridade, uma supervalorização daquilo que o seio é e significa, um modo de mantê-lo de certa maneira à parte, à margem ou entre parêntesis?” (CALVINO, 1994, p.14). E, dessa forma, rompe com os limites estabelecidos pelos preconceitos e tabus da narrativa clássica: "O peso morto de uma tradição de maus costumes impede-a de apreciar em seu 
justo mérito as intenções mais esclarecidas' conclui amargamente Paloma”. (CALVINO, 1994, p.14)

O autor de Palomar tira a roupa da narrativa clássica e veste de outras roupagens sua narrativa. Lyotard (1986, p.26) considera “[...] 'pós-moderna' a incredulidade em relação aos metarrelatos" legitimadores, repletas de heróis, grandes perigos e périplos. Para ele, na pós-modernidade, a função narrativa se dispersa em jogos de linguagem que veiculam validades pragmáticas. Calvino (1994), com o olhar múltiplo, como a natureza da sua própria obra, num momento de extrema liberdade, cria um texto múltiplo e apresenta-se como um visionário ao construir o novo com restos do presente vivido.

\section{CONSIDERAÇÕES FINAIS (?)}

Ítalo Calvino escreve sua leitura/olhar sobre a realidade contemporânea que o cerca e é justamente isso que torna sua narrativa possível de ser lida da perspectiva das teorias do pós-moderno. É a partir da experiência do vivido que o narrador observa e veste seu olhar sobre a realidade pós-industrial, pós-colonial, globalizada. Do seu olhar não escaparam a relação homem X máquina, o Eros eletrônico, o trabalho da citação, o narrador pós-moderno, os conceitos característicos da situação pós-moderna.

Também por ser metafórica e metonímica, a narrativa tornou-se plural. Nesse sentido, Rosa (1987, p.16) afirmou que com o intento de escapar ao autoritarismo de sentido reivindicamos sempre a multiplicidade das leituras, a pluralidade dos sentidos, as várias interrogações. Neste trabalho, procuramos escrever uma das leituras possíveis desta obra. O nosso olhar procurou ser, também, um instrumento de revelação das imagens criadas. Ítalo Calvino, enquanto autor pós-moderno, valorizou o sentido da visão na criação da sua narrativa, transformando-a em ficção-crítica, na medida em que as metáforas usadas podem ser lidas como nós as lemos, ou de várias outras formas. Até porque esta obra é um gramado sem limite, situada literalmente no cenário pósmoderno.

\section{REFERÊNCIAS}

ARRIGUCCI Jr., Davi. Enigma e comentário: ensaios sobre literatura e experiência. São Paulo: Companhia das Letras, 1987. p. 227-235. 
BARTHES, Roland. O rumor da língua. Tradução de António Gonçalves. Lisboa, Portugal: Edições 70, 1984. p.27-29, 49-53.

. S/Z: uma análise da novela Sarrasine de Honoré de Balzac. Tradução de Léa Novaes. Rio de Janeiro: Nova Fronteira, 1988, p. 43-51.

BAUMANN, Zygmunt. Globalização: as conseqüências humanas. Tradução de Marcus Penchel Rio, Jorge Zahar editor, 1999.

BLANCHOT, Maurice. O espaço literário. Rio de Janeiro: Rocco, 1987. p.191-207.

CALVINO, Ítalo. Palomar. Tradução de Ivo Barroso. São Paulo: Companhia das Letras, 1994.

GUMBRECHT, Hans Ulrich. Corpo e forma: ensaios para uma crítica não hermenêutica. Tradução de Lawrence Flores Pereira.Rio de Janeiro. UERJ, 1998.

HUYSSEN, Andréas. Mapeando o pós-moderno. Tradução de Carlos A. de C.Moreno). In: . HOLANDA, H.B.de. (Org.) Pós-Modernismo e política. Rio de Janeiro: Rocco, 1992.

LYOTARD, Jean-François. O pós-moderno. Tradução de Ricardo Correa Barbosa. Rio de Janeiro: José Olympio, 1986.

ROSA, Nicolas. Los fulgores del simulacro. In: Cuadernos de Extension Universitária, n.15, Argentina: Univerdad Nacional del Litoral, 1987, p. 8-19.

SANTIAGO, Silviano. Nas malhas da letra. São Paulo: Companhia das Letras, 1989.

SUCRE, Guillermo. A nova crítica. In: MORENO, C. F. América latina em sua literatura. São Paulo: Perspectiva, 1979, p. 261-278. 